\title{
Direct oral anticoagulants for treatment and prevention of venous thromboembolism in cancer patients
}

This article was published in the following Dove Press journal: Vascular Health and Risk Management

\author{
Andrew B Song' \\ Rachel P Rosovsky' \\ Jean M Connors ${ }^{2}$ \\ Hanny Al-Samkari \\ 'Division of Hematology, Massachusetts \\ General Hospital, Harvard Medical \\ School, Boston, MA, USA; '2Division of \\ Hematology, Brigham and Women's \\ Hospital, Harvard Medical School, \\ Boston, MA, USA
}

\begin{abstract}
Venous thromboembolism (VTE) is a common cause of morbidity and mortality in patients with cancer. Compared with the general population, cancer patients with VTE have higher rates of both VTE recurrence and bleeding. While low molecular weight heparin (LMWH) has been the mainstay of treatment for cancer-associated VTE for over a decade, direct oral anticoagulants (DOACs) have recently emerged as a new therapeutic option due to their ease of administration and because they do not require laboratory monitoring. Several large randomized clinical trials have been performed or are ongoing at the time of writing, comparing DOACs with LMWH in this population. Three of these trials have thus far been published and suggest that DOACs are a reasonable alternative to LMWH for management of cancer-associated VTE. Despite the advantages offered by DOACs, these agents may not be appropriate for certain patient groups owing to increased risk of bleeding, organ compromise, extremes of weight, and other issues. Finally, data are emerging suggesting that DOACs may be useful for primary thromboprophylaxis in cancer patients in conjunction with validated risk assessment scores. In this evidence-based review, data for the use of DOACs to treat cancer-associated VTE will be examined, focusing on efficacy, safety, and timing of treatment. Guidance on choosing the optimal anticoagulant for a given patient is also offered.
\end{abstract}

Keywords: venous thromboembolism, malignancy, thrombosis, rivaroxaban, apixaban, edoxaban, DOAC

\section{Introduction}

Venous thromboembolism (VTE) is a major cause of morbidity and mortality in cancer patients. While anticoagulation for cancer-associated VTE was limited to vitamin $\mathrm{K}$ antagonists (VKAs) and heparin agents for several decades, the direct oral anticoagulants (DOACs) have recently emerged as a new therapeutic option. Because no agent has demonstrated consistent superiority over the others in managing these patients, the clinician must consider issues including efficacy in preventing VTE recurrence, bleeding risk, interactions with cancer-directed treatments, route of administration, financial cost, and utility of monitoring. ${ }^{1}$ As such, deciding on optimal anticoagulation is complex and patient specific. Irrespective of agent choice, anticoagulation is more challenging in cancer patients, who demonstrate greater rates of VTE occurrence as well as increased rates of bleeding complications with anticoagulation compared with non-cancer patients.
Correspondence: Hanny Al-Samkari

Division of Hematology, Massachusetts General Hospital, Zero Emerson Place Suite II8 Office II2, Boston, MA 02II4, USA

$\mathrm{Tel}+|61764362| 4$

$\mathrm{Fax}+16176438840$

Email hal-samkari@mgh.harvard.edu 
For over a decade, low molecular weight heparin (LMWH) has been the standard of care treatment for cancer-associated VTE after pivotal clinical trials demonstrated lower rates of VTE recurrence compared with warfarin. However, LMWH therapy is associated with higher costs. Furthermore, injections frequently impact quality of life, which may reduce patient adherence. In recent years, the DOACs, which include the direct thrombin inhibitor dabigatran and the direct factor Xa inhibitors apixaban, edoxaban, and rivaroxaban, have emerged as the standard agents for treatment of VTE in the non-cancer population following several large, randomized controlled trials demonstrating non-inferiority to warfarin. ${ }^{2-6}$ Consequently, these agents are an attractive alternative to LMWH to treat cancer patients.

In addition to initial anticoagulation for VTE in the cancer patient, primary prophylaxis and extended anticoagulation beyond the initial 6-12 months of treatment are important considerations. In cancer patients, DOACs have gained attention for their possible utility as primary prophylaxis for high-risk patients in conjunction with the strategic use of clinical prediction scores.

In this evidence-based review, we will discuss the challenges of anticoagulation in the cancer population, review the evolution of anticoagulation options for cancer-associated VTE, explore the most recent data for use of DOACs in cancer patients, and explore the use of DOACs for primary thromboprophylaxis and for extended anticoagulation beyond the initial treatment period.

\section{Thromboembolism and unique challenges in the cancer population}

While rates vary depending upon several patient and malignancy-related characteristics, VTE is common in the cancer population. Malignancy accounts for $20-30 \%$ of initial VTE events ${ }^{7,8}$ and VTE occurs in approximately $20 \%$ of cancer patients. ${ }^{8-12}$ Cancer treatments, including cytotoxic chemotherapy, targeted therapy, hormonal therapy, radiation therapy, and surgery, may further increase VTE risk. ${ }^{13}$ Altogether, this represents a four- to sevenfold increased risk of VTE relative to patients without cancer. Not only is VTE risk increased in patients with cancer but cancer patients with VTE have more hospitalizations, a higher rate of metastatic disease, and worse overall survival compared to cancer patients without VTE across multiple tumor types. ${ }^{14,15}$ VTE is the second leading cause of death in cancer patients, behind only the malignancy itself. ${ }^{13}$ The thrombophilic stimulus of malignancy may be exceedingly difficult to control in some cancer patients, even with consistent, therapeutic levels of anticoagulation. ${ }^{16,17}$

Although anticoagulation is frequently effective in managing VTE in cancer patients, complications of anticoagulation are more frequent and severe in this population. Cancer patients have a three- to four-fold higher rate of VTE recurrence compared to patients without cancer. ${ }^{18,19}$ Anticoagulated cancer patients also have a two- to threefold increased rate of major bleeding compared to anticoagulated patients without cancer. ${ }^{18,20,21}$ These findings may be related to drug-drug interactions with cancer-directed treatments, nausea, poor oral intake, thrombocytopenia, and metabolic derangements affecting anticoagulant levels. ${ }^{22,23}$ Cost and access-related issues may present a greater burden in cancer patients as well.

\section{LMWH for treatment of cancer- associated VTE}

For over a decade, consensus guidelines have established LMWH as the standard of care for initial treatment of cancer-associated VTE. ${ }^{24-27}$ This recommendation is based on evidence from five randomized, controlled trials that compared LMWH to VKAs, as summarized in Table 1. In addition, meta-analyses of these randomized controlled trials comparing LMWH and VKA demonstrated that LMWH reduces the recurrence of VTE compared to $\mathrm{VKAs}^{28,29}$ but may increase the risk of major bleeding.

The two major trials comparing LMWH with warfarin for cancer-associated VTE had disparate findings. The CLOT trial ${ }^{22}$ demonstrated a statistically significant reduction in VTE recurrence rate compared with warfarin, while the CATCH trial, ${ }^{30}$ the largest and most recent study to date, did not show superiority of LMWH. However, assessment of the cancer burden and pre-existing risk of VTE may help to explain the difference observed in these two trials. There were higher proportions of patients with metastatic disease, ongoing cancer treatment, and overall mortality in the CLOT trial compared to the CATCH trial, suggesting that the patient populations of the two trials were not similar. As discussed previously, cancer severity influences both VTE recurrence and bleeding rates independent of anticoagulation. ${ }^{18,21}$ The CATCH patient population was less likely to develop recurrent VTE than the CLOT population and this may have decreased the power of the trial to detect a significant difference in event rates; 
Table I Summary of major trials comparing LMWH with VKAs

\begin{tabular}{|c|c|c|c|}
\hline Trial & $\begin{array}{l}\text { VTE recur- } \\
\text { rence }(\%)\end{array}$ & $\begin{array}{l}\text { Major } \\
\text { bleeding (\%) }\end{array}$ & $\begin{array}{l}\text { Mortality } \\
\text { (\%) }\end{array}$ \\
\hline CANTHANOX ${ }^{84}$ & 4.0 vs 2.8 & 16.0 vs 7.0 & $\begin{array}{l}22.7 \text { vs } \\
11.3\end{array}$ \\
\hline $\begin{array}{l}\text { Warfarin vs enoxa- } \\
\text { parin } \\
\text { ( } 3 \text { months) }\end{array}$ & \multicolumn{3}{|c|}{$\begin{array}{l}\text { No significant difference in primary combined } \\
\text { outcome of major bleeding or VTE recurrence. } \\
\text { Increased rate of fatal bleeds in warfarin arm } \\
(8 \% \text { vs } 0 \%)\end{array}$} \\
\hline CLOT $^{22}$ & 17 vs 9 & 4 vs 6 & 39 vs $4 I$ \\
\hline $\begin{array}{l}\text { VKA vs dalteparin } \\
\text { ( } 6 \text { months) }\end{array}$ & \multicolumn{3}{|c|}{$\begin{array}{l}\text { Significant reduction in VTE recurrence with } \\
\text { dalteparin. No significant difference in major } \\
\text { bleeding or mortality. The } 12 \text {-month post-hoc } \\
\text { analysis showed a probability of death of } 20 \% \\
\text { in the dalteparin arm compared with } 36 \% \text { in } \\
\text { the VKA arm }(p=0.03)^{85}\end{array}$} \\
\hline ONCENOX ${ }^{86}$ & 6.5 vs 10.0 & 2.9 vs 9.0 & $\begin{array}{l}32.4 \text { vs } \\
32.8\end{array}$ \\
\hline $\begin{array}{l}\text { Warfarin vs enoxa- } \\
\text { parin } \\
\text { (7 months) }\end{array}$ & \multicolumn{3}{|c|}{$\begin{array}{l}\text { Owing to small event rates, no trends or sig- } \\
\text { nificance could be reported }\end{array}$} \\
\hline LITE $^{87}$ & 16.0 vs 7.0 & 7.0 vs 7.0 & $\begin{array}{l}47.0 \text { vs } \\
47.0\end{array}$ \\
\hline $\begin{array}{l}\text { VKA vs tinzaparin } \\
\text { (12 months) }\end{array}$ & \multicolumn{3}{|c|}{$\begin{array}{l}\text { No difference in VTE recurrence or major } \\
\text { bleeding after } 3 \text { months. After } 12 \text { months of } \\
\text { therapy for patients meriting continuation, } \\
\text { post-hoc analysis showed significantly lower } \\
\text { VTE recurrence in the tinzaparin arm }\end{array}$} \\
\hline CATCH $^{30}$ & 10.5 vs 7.2 & 2.4 vs 2.7 & $\begin{array}{l}32.2 \text { vs } \\
34.7\end{array}$ \\
\hline $\begin{array}{l}\text { Warfarin vs tinza- } \\
\text { parin } \\
\text { ( } 6 \text { months) }\end{array}$ & \multicolumn{3}{|c|}{$\begin{array}{l}\text { No statistically significant difference in rates of } \\
\text { VTE recurrence and major bleeding. Significant } \\
\text { reduction in rates of non-major bleeding in the } \\
\text { tinzaparin arm }\end{array}$} \\
\hline
\end{tabular}

Abbreviations: $\mathrm{LMWH}$, low molecular weight heparin; VKA, vitamin $\mathrm{K}$ antagonist; VTE, venous thromboembolism.

in fact, the observed rate of thrombotic events in $\mathrm{CATCH}$ was lower than expected. The same analysis with a higherrisk population like that of CLOT may have duplicated the results of the CLOT trial.

While it is true that the more morbid CLOT patient population may have had greater difficulty achieving international normalized ratio (INR) goals owing to poor oral intake, emesis, and alterations in metabolism due to interactions with chemotherapies, the time in therapeutic range (TTR) for the warfarin groups was comparable between CLOT and CATCH (46\% and $47 \%$, respectively) as was the time above INR therapeutic range. While failure of VKA management is an important consideration in the management of ill cancer patients, this is a less likely explanation for the discrepancy between CLOT and $\mathrm{CATCH}$.

Nevertheless, despite the consensus guidelines from professional societies recommending the use of LMWH for cancer-associated thrombosis, indefinite treatment with LMWH has faced numerous real-world hurdles. A recent insurance database analysis showed that almost half of cancer patients with a primary VTE were started on warfarin as opposed to around $25 \%$ each for LMWH and rivaroxaban. ${ }^{31}$ This may be due in part to lower cost and ease of oral administration, but patient and provider preference to avoid the pain, bruising, and hematomas that come with injection of LMWH has also been demonstrated in real-world data. Median treatment duration for LMWH is also less than half that of warfarin and rivaroxaban (3.3, 7.9, and 7.9 months, respectively). ${ }^{31}$ These findings are particularly consequential for those patients with a limited life expectancy. Therefore, despite consensus guidelines from professional societies recommending LMWH, patient and provider adherence is suboptimal. Therefore, additional safe, effective anticoagulant choices are necessary for cancer patients.

\section{DOACs for treatment of cancer- associated VTE}

The results of several large, pivotal, randomized controlled trials have demonstrated the non-inferiority of DOACs to warfarin for prevention of VTE recurrence as well as lower rates of bleeding in the general population..$^{2-6,32}$ In turn, DOACs have replaced warfarin as the standard of care for treatment of VTE in the majority of non-cancer patients. The pivotal trials establishing DOACs as standard of care for VTE treatment in the non-cancer population each contained only a small subset of cancer patients. A metaanalysis of the cancer patients from six of these phase III clinical trials found significantly lower VTE recurrence in the DOAC arm compared with the VKA arm (relative risk $0.57,95 \%$ CI $0.36-0.91$ ) with a similar risk of major bleeding, ${ }^{32}$ while another meta-analysis examining the same cancer patient subpopulation from these six trials did not find a significant reduction in VTE recurrence. These meta-analyses may not be generalizable to the cancer population at large as several of the trials did not include patients with active cancer (for which the definition was variable), and no data on the type and stage of cancer or use of cancer-directed treatments were described. Despite these 
limitations, the findings from these subgroup analyses suggest that DOACs may be appropriate for cancer patients, or at least certain groups of cancer patients.

To study the cancer population directly, several multicenter randomized controlled trials comparing direct $\mathrm{Xa}$ inhibitors with LMWH for initial treatment of cancerassociated VTE have been published (two as complete publications and one in abstract form, summarized in Table 2) or are currently underway at the time of writing.

\section{Hokusai VTE Cancer trial}

This worldwide study randomized 1,050 cancer patients with proximal deep vein thrombosis (DVT), acute symptomatic pulmonary embolism (PE), or incidental PE to 5 days of LMWH followed by either oral edoxaban $(60 \mathrm{mg}$ once daily) or subcutaneous dalteparin (200 IU/kg once daily for 1 month, then $150 \mathrm{IU} / \mathrm{kg}$ once daily) for a period of 6-12 months. ${ }^{33}$ The study utilized a composite primary outcome of recurrent VTE or major bleeding. Edoxaban was noninferior to dalteparin $(12.8 \%$ vs $13.5 \%, p=0.006$ for noninferiority). VTE recurrence was not significantly different between edoxaban and dalteparin $(7.9 \%$ vs $11.3 \%, p=0.09)$. Major bleeding occurred more often in the edoxaban group compared with dalteparin ( $6.9 \%$ vs $4.0 \%, p=0.04)$. Clinically relevant non-major bleeding (CRNMB) was also higher in the edoxaban arm (14.6\%) compared with the dalteparin arm (11.1\%), but this difference did not reach statistical significance. Overall survival was similar between the two groups.

\section{SELECT-D trial}

This worldwide study compared rivaroxaban $(15 \mathrm{mg}$ twice daily for 3 weeks, then $20 \mathrm{mg}$ daily for a total of 6 months) with dalteparin (200 IU/kg daily for 1 month, then $150 \mathrm{IU} / \mathrm{kg}$ daily for 5 months) in 406 patients with active cancer and PE (symptomatic or incidental) or proximal DVT. ${ }^{34}$ The primary outcome was VTE recurrence. Rivaroxaban had a lower rate of VTE recurrence than dalteparin (4\% vs $11 \%$, HR 0.43 , 95\% CI 0.19-0.99). Rates of major bleeding were not significantly different (4\% vs 6\%, HR 1.83, 95\% CI 0.68-4.96). However, CRNMB rates were significantly higher in the rivaroxaban arm (13\% vs 4\%, HR 3.74, 95\% CI $1.63-$ 8.69). Overall survival was similar between the two groups.

\section{ADAM VTE trial}

The ADAM VTE trial is the first study comparing a DOAC to LMWH for treatment of cancer-associated VTE that had major bleeding as its primary outcome, with VTE recurrence and a composite of major bleeding plus CRNMB as secondary outcomes. This study was published in abstract form in 2018. ${ }^{35}$ This phase IV randomized controlled superiority trial compared apixaban (10 mg twice daily followed by $5 \mathrm{mg}$ twice daily) with dalteparin (200 IU/kg daily for 1 month followed by $150 \mathrm{IU} / \mathrm{kg}$ once daily) for 6 months in 300 patients with cancer-associated VTE. ${ }^{36}$ Based on the published abstract, apixaban was associated with significantly lower VTE recurrence compared with dalteparin $(3.4 \%$ vs $14.1 \%$, HR 0.26, 95\% CI 0.09-0.80, $p=0.02$ ). Major bleeding was not significantly different between the apixaban and dalteparin arms $(0.0 \%$ vs $2.1 \%, p=0.01)$, nor was the combined major bleeding and CRNMB rate $(6.2 \%$ vs $6.3 \%$, HR $0.91,95 \%$ CI $0.41-1.94, p=0.88)$. Overall survival was similar between the two groups. Quality of life surveys as well as bruising questionnaires favored apixaban. While final results from this study are awaited, the published abstract suggests the safety and efficacy of apixaban for treatment of cancerassociated VTE.

Table 2 Summary of major trials comparing DOACs with LMWH

\begin{tabular}{|c|c|c|c|c|}
\hline Trial & VTE recurrence (\%) & Major bleeding (\%) & Clinically relevant non-major bleeding (\%) & Mortality (\%) \\
\hline Hokusai VTE Cancer ${ }^{33}$ & 8.8 vs 6.5 & 3.2 vs 5.6 & 8.2 vs 12.3 & 24.2 vs 24.8 \\
\hline Dalteparin vs edoxaban & \multicolumn{4}{|c|}{$\begin{array}{l}\text { Edoxaban was non-inferior to LMWH in combined outcome of VTE recurrence or major bleeding. Major bleeding } \\
\text { occurred more often in the edoxaban group. Rates of non-major bleeding were not significantly different, nor was } \\
\text { mortality }\end{array}$} \\
\hline SELECT-D ${ }^{34}$ & II vs 4 & 4 vs 6 & 4 vs 13 & 30 vs 25 \\
\hline Dalteparin vs rivaroxaban & \multicolumn{4}{|c|}{$\begin{array}{l}\text { Rivaroxaban had a significantly lower rate of VTE recurrence. Rates of major bleeding were not significantly different } \\
\text { although rates of non-major bleeding were significantly higher in the rivaroxaban arm. No difference in mortality }\end{array}$} \\
\hline ADAM VTE ${ }^{35}$ & I4.I vs 3.4 & 2.1 vs 0.0 & 4.2 vs 6.2 & 10.6 vs 15.9 \\
\hline Dalteparin vs apixaban & \multicolumn{4}{|c|}{ Significant reduction in VTE recurrence with apixaban. No significant difference in bleeding rates or mortality } \\
\hline
\end{tabular}

Note: Six-month study outcomes are reported for all trials.

Abbreviations: DOAC, direct oral anticoagulant; LMWH, low molecular weight heparin; VTE, venous thromboembolism. 
Unlike the pivotal trials comparing DOACs to VKAs in the general population, these trials had strict inclusion criteria for patients with active cancer. The patient populations of all three trials had rates of mortality, active cancer-directed treatment, and metastatic disease comparable to those of the aforementioned LMWH vs VKA trials, signifying a representative cancer population. The results of these three studies suggest that DOACs are at least non-inferior to LMWH for preventing VTE recurrence in the cancer population. This conclusion has been corroborated by six recent metaanalyses $^{28,29,37-40}$ as well as several cohort analyses describing the efficacy of DOACs in clinical practice.

However, both Hokusai VTE Cancer and SELECT-D, as well as the meta-analyses, observed increased bleeding events, including numerous gastrointestinal (GI) bleeds, in the DOAC arms. These findings are consistent with prior trials examining DOACs for treatment of VTE, ${ }^{32}$ as well as trials examining DOACs for stroke prevention in patients with atrial fibrillation. ${ }^{41-43}$ Many of the bleeding events occurred in patients with esophageal and gastric cancers. A safety analysis of the first 220 patients in the SELECT-D trial observed a non-significant difference in major bleeding (especially upper GI bleeding) between the rivaroxaban and dalteparin arms in patients with cancers of the esophagus or gastroesophageal junction; patients with these cancers were subsequently excluded for the remainder of the trial. Similarly, subgroup analysis of the Hokusai VTE Cancer trial demonstrated that in patients with GI cancer, there was a higher risk of major bleeding events in the edoxaban arm than in the dalteparin arm (12.7 vs $3.6 \%$, HR $4.0,95 \%$ CI $1.5-10.6, p=0.005$ ), most of which were GI bleeds. ${ }^{44} \mathrm{~A}$ recent claims database analysis of 26,894 patients with cancer-associated $\mathrm{VTE}^{45}$ corroborated these results by showing heterogeneity in bleeding risk with DOACs by cancer type, with upper GI cancers having the highest rate (8.6\% per patient-year). Lower rates were observed in lung cancer $(6.0 \%)$, colorectal cancer $(4.5 \%)$, prostate cancer $(4.0 \%)$, hematological cancer $(3.5 \%)$, and breast cancer $(2.9 \%)$. Of note, when stratified by cancer type, there was a borderline but nonsignificant increased bleeding risk for DOACs vs LMWH in patients with upper GI cancers. A recent study examining longer-term rivaroxaban treatment of cancer-associated VTE echoes these findings: over a 3-year observation period, a considerably lower rate of bleeding relative to those of the DOAC arms in Hokusai VTE Cancer and SELECT-D was achieved by excluding patients with GI or genitourinary malignancies. ${ }^{46}$ Overall, the results from many of these studies raise questions about the appropriateness of DOAC use in patients with GI cancers, or at least the appropriateness of rivaroxaban or edoxaban use. In addition, the somewhat provocative findings of superiority of apixaban without increased bleeding in the ADAM VTE trial suggest that the specific direct factor Xa inhibitor employed may matter and that results of each study examining a specific agent may not be generalizable across the class of direct factor Xa inhibitors. The possible difference in bleeding events with apixaban versus edoxaban or rivaroxaban in the cancer patient population will be addressed by the Caravaggio study. ${ }^{47}$

Notably, each of these trials excluded certain subpopulations of cancer patients: those with Eastern Cooperative Oncology Group (ECOG) performance status of 3 or 4, those with brain metastases, and those with thrombocytopenia (platelet count of $<50 \times 10^{9} / \mathrm{L}$ ) are some notable examples. A retrospective study published in 2019 found no increase in bleeding rates in patients with primary brain tumors or brain metastases in patients receiving DOACs compared with those receiving $\mathrm{LMWH},{ }^{48}$ but many of the subpopulations excluded from the aforementioned trials remain unstudied. It remains unclear whether DOACs are safe and of similar efficacy in these patient subpopulations.

Ongoing randomized controlled open-label trials examining DOACs for cancer-associated thrombosis will help to clarify many outstanding questions. These trials include the Caravaggio study (NCT03045406), comparing apixaban with dalteparin; the CANVAS trial (NCT02744092), comparing DOAC therapy (rivaroxaban, apixaban, edoxaban, or dabigatran, by investigator's choice) with LMWH with or without a transition to warfarin; the CONKO-0211 (NCT02583191) and CASTA-DIVA (NCT02746185) studies, comparing rivaroxaban with LMWH; and the singlearm CAP study (NCT02581176), investigating the use of apixaban as treatment for cancer-associated thrombosis. Information gathered from these trials will further inform clinicians regarding the efficacy and safety profile of DOACs as anticoagulation for cancer-associated VTE.

\section{Choosing between DOACs and other anticoagulants for VTE management}

As new data are published, management strategies for cancerassociated VTE are evolving quickly. DOACs represent an attractive alternative to the well-established LMWH, expanding the armamentarium of anticoagulants studied in cancer 
patients. At the time of writing, most consensus guidelines still favor LMWH, but this is beginning to change. In 2018, the International Society for Thrombosis and Haemostasis (ISTH) became the first major body to suggest the use of DOACs for cancer patients with an acute diagnosis of VTE, a low risk of bleeding, and no drug-drug interactions with current systemic therapy. ${ }^{49}$ National Comprehensive Cancer Network (NCCN) guidelines now recommend rivaroxaban as a monotherapy option, apixaban "for patients who refuse or have compelling reasons to avoid LMWH", as well as edoxaban following a lead-in with heparin agents (category 1 evidence). ${ }^{50} \mathrm{New}$ guidelines from the American Society of Hematology (ASH) are expected in late 2019. It is important to note that while DOACs are favorable in many ways (fixed-dose regimens without laboratory monitoring, fewer interactions with cancer therapies, ${ }^{51}$ oral route of administration), this does not mean that they will be universally preferred for all cancer patients.

The major aspect of DOACs that makes them attractive relative to LMWH is oral administration. In the SELECT-D trial, the median duration of assigned treatment was shorter with dalteparin primarily owing to the inconvenience of injections. An interview analysis of patients, also from the SELECT-D trial, however, showed that most patients found injections straightforward and acceptable as an element of holistic cancer care, contrary to these findings. ${ }^{52}$ In addition, a choice-based conjoint exercise showed that preference for oral administration over injection was relatively mild; minimal interference with cancer treatment, low thrombosis recurrence rate, and low risk of major bleed were most valued by the patients. ${ }^{53}$ An international survey of over 500 physicians and 800 patients showed that clinicians greatly overestimate their patients' expected perceived burden of daily subcutaneous injections. ${ }^{54}$ Just as cancer patients being treated for VTE strongly value effectiveness and safety in addition to comfort, so too must clinicians in discussing with patients their individual preferences. $^{55}$

In addition, while there is high awareness of drug interactions with VKAs, there is a relative lack of data regarding DOACs' interactions with anticancer medications. Dabigatran is metabolized via P-glycoprotein pathways, while rivaroxaban and apixaban are also metabolized by the CYP3A4 and CYP2J2 pathways; none of the currently approved DOACs are known to affect the activity of these metabolic pathways themselves. To date, the clinical significance of DOAC interactions with other medications in general is relatively unknown and there are few published clinical data on interactions with anticancer medications. ${ }^{56,57}$ It is important to recognize that although there are several drugs that may modulate plasma levels of DOACs, there is a lack of pharmacokinetic data regarding specific drug interactions. On a theoretical basis, clinicians should be cautious when utilizing chemotherapies or other medications (e.g., antifungals) which may influence DOAC metabolism. In addition, chemotherapies may influence the bioavailability of DOACs because of side effects. For instance, the increased risk of GI bleeds observed with DOACs may make these medications less favorable in patients taking anticancer agents that disrupt the GI mucosa, potentially increasing absorption.

In the case of elderly or more frail patients for whom significant bleeds can be highly morbid, reversibility of anticoagulation is another important consideration. Reversal agents are available for DOACs. Idarucizumab is an Fab antibody fragment approved to rapidly reverse the effects of dabigatran. ${ }^{58}$ Andexanet alfa is a recombinant modified human FXa protein which acts as a decoy to bind factor Xa inhibitors, thereby dramatically reducing anti-Xa activity. ${ }^{59}$ Currently, andexanet is not readily available in many US hospitals and is extremely expensive. Ciraparantag (PER977, Perosphere) is a small, synthetic, water-soluble, cationic molecule currently under development. It was originally designed to reverse the effects of unfractionated heparin and LMWH but has also been shown to reverse the effects of DOACs. ${ }^{60}$ Importantly, many of these DOAC reversal agents have associated thrombosis and mortality risks, as demonstrated in clinical trials evaluating their use, but an in-depth discussion of anticoagulation reversal is beyond the scope of this article.

Poor renal function associated with age or chemotherapyassociated renal toxicity may preclude the use of both LMWH and DOACs. Currently, dabigatran is not recommended for patients with low creatinine clearance while apixaban and rivaroxaban can be used with significant caution. ${ }^{61} \mathrm{LMWH}$, unlike unfractionated heparin, is primarily renally excreted and is therefore also used with significant caution in patients with poor renal function. ${ }^{23}$ In select cancer patients with poor renal function, LMWH can be administered in reduced doses with close monitoring of anticoagulation with anti-Xa levels. Notably, the degree of renal dysfunction correlates with the risk of major bleeding in cancer patients, ${ }^{62}$ making the optimal choice of anticoagulant and its associated safety profile an important consideration. For some of these patients, warfarin may be the best choice as it is the only agent that can be readily monitored.

Optimal selection of anticoagulation for treatment of cancer-associated thrombosis may take into account several of the above clinical considerations, which are summarized in Table 3. This list is not exhaustive and treatment 
decisions should be individualized treatment considering both provider recommendations and patient values.

\section{DOAC utility for primary prophylaxis of VTE}

Although current clinical guidelines from the American Society of Clinical Oncology ${ }^{63}$ recommend primary thromboprophylaxis (i.e., before any VTE event) in

Table 3 Clinical considerations for selection of anticoagulation

\begin{tabular}{|c|c|c|}
\hline \multirow[t]{2}{*}{ DOAC } & Optimal & $\begin{array}{l}\text { - Patient without GI malignancy }{ }^{33,34} \\
\text { - Low risk of major bleeding } \\
\text { - Ease of treatment for patient is a priority }{ }^{31} \\
\text { - No strong drug--drug interactions }\end{array}$ \\
\hline & Avoid & $\begin{array}{l}\text { - Active Gl malignancy }{ }^{33,34} \\
\text { - History of Gl bleeding }{ }^{33,34} \\
\text { - Extremes of weight }(<50 \mathrm{~kg} \text { or }>150 \mathrm{~kg})^{\mathrm{b}} \\
\text { - Renal insufficiency/fluctuating renal status }\end{array}$ \\
\hline \multirow[t]{2}{*}{ LMWH } & Optimal & $\begin{array}{l}\text { - Frequent emetogenic chemotherapy, nausea } \\
\text { and vomiting, difficulty with oral intake } \\
\text { - Concerns for GI absorption (feeding tubes, } \\
\text { gastric or bowel resections) } \\
\text { - Drug--drug interactions with DOAC or VKA } \\
\text { - Motivated patient willing to use for extended } \\
\text { durations }{ }^{31} \\
\text { - Known increased bleeding risk } \\
\text { - Recurrent cancer-associated VTE while on } \\
\text { anticoagulants }{ }^{\text {c8-90 }}\end{array}$ \\
\hline & Avoid & $\begin{array}{l}\text { - Strong aversion to injectable therapy }{ }^{31} \\
\text { - Renal insufficiency/fluctuating renal status } \\
\text { - Extremes of weight }(<50 \mathrm{~kg} \text { or }>150 \mathrm{~kg})^{\mathrm{b}}\end{array}$ \\
\hline \multirow[t]{2}{*}{ VKA } & Optimal & $\begin{array}{l}\text { - Any situation in which close anticoagulant } \\
\text { monitoring is necessary (eg, multiple prior } \\
\text { bleeds) or concern about absorption and } \\
\text { metabolism } \\
\text { - Advanced chronic kidney disease } \\
\text { - Extremes of weight }(<50 \mathrm{~kg} \text { or }>150 \mathrm{~kg})^{\mathrm{b}}\end{array}$ \\
\hline & Avoid & $\begin{array}{l}\text { - Lack of access to dedicated anticoagulation } \\
\text { monitoring service with experience caring } \\
\text { for cancer patients }\end{array}$ \\
\hline
\end{tabular}

Notes: alf a DOAC reversal agent is not readily available, LMWH may be preferred for patients with increased risk of bleeding at baseline. 'Prescribing information for factor $\mathrm{Xa}$ inhibitors and $\mathrm{LMWH}$ recommend against use in extremes of weight, although a 2018 study suggests that DOACs may be appropriate for obese patients.-

92 CUsing twice-daily dosing of enoxaparin, given at 120-125\% of standard twicedaily dosing. No data for DOACs in this setting are available, and how to increase the DOAC dose with limited pill strengths is not known. Please note: This is not an exhaustive list. Anticoagulant choices may be appropriate in some patients not meeting "optimal" criteria. Reproduced from Al-Samkari H, Connors JM. The role of direct oral anticoagulants in treatment of cancer-associated thrombosis. Cancers (Basel). 2018;10 (8). Creative Commons license and disclaimer available from: http://creativecommons.org/licenses/by/4.0/legalcode. '

Abbreviations: $\mathrm{Gl}$, gastrointestinal; DOAC, direct oral anticoagulant; VKA, vitamin $\mathrm{K}$ antagonist; VTE, venous thromboembolism; LMWH, low molecular weight heparin. hospitalized patients with active cancers, it is not recommended in the routine outpatient setting owing a higher number needed to treat of 40 to 50 (with the exception of myeloma patients receiving treatment with immunomodulatory agents). ${ }^{64}$ However, these guidelines do indicate that thromboprophylaxis may be considered for select high-risk patients. Several characteristics may inform which patients are high risk. In particular, tumor site of origin is associated with different risks of VTE, with pancreatic ductal adenocarcinoma and gastric adenocarcinoma carrying the highest risk. ${ }^{65-67}$ Stage also informs the risk of VTE; patients with metastatic disease have a 20fold increased risk of VTE compared to those without cancer. ${ }^{9}$ Molecular biomarkers such as tissue factor, ${ }^{68} \mathrm{D}$ dimer, ${ }^{69}$ and P-selectin ${ }^{70}$ have also been shown to predict an increased risk of cancer-associated VTE. Ongoing use of regression analyses and forward selection of candidate variables will continue to best identify other clinical criteria that may be useful in predicting the risk of cancerassociated VTE. ${ }^{71}$

Numerous clinical prediction scores have been created to best identify those patients who may merit primary prophylaxis given their individual risk profiles. The Khorana score was the first clinical prediction score to predict VTE risk specifically in cancer patients and is the most widely utilized. Advantages of the Khorana score include its relative simplicity, successful validation in multiple studies, ${ }^{67,72,73}$ and high negative predictive value, allowing clinicians to effectively exclude low-risk patients from thromboprophylaxis and associated bleeding risks. ${ }^{12}$ Relative limitations include a low positive predictive value, a need for further risk stratification (most patients are classified as intermediate risk), and lack of consistent validity in single sites of cancers. Other clinical prediction scores that modify the original Khorana score include the Protecht score ${ }^{74}$ and the Vienna score. ${ }^{75}$ The clinical characteristics of interest for each of these scores are summarized in Table 4.

Recent clinical trials (summarized in Table 5) have examined the utility of DOACs, in conjunction with clinical prediction scores, for primary thromboprophylaxis in high-risk cancer patients. The AVERT trial ${ }^{76}$ is a randomized, placebo-controlled, double-blind clinical trial comparing 6 months of apixaban (2.5 mg twice daily) with placebo in 574 patients with a Khorana score $\geq 2$. Patients with conditions predicting an increased risk of significant bleeding, hepatic dysfunction, renal insufficiency, and thrombocytopenia were excluded. The primary efficacy outcome of VTE occurrence rate was lower in the 
Table 4 Clinical prediction scoring tools for venous thromboembolism risk in cancer patients

\begin{tabular}{|l|l|}
\hline Score & Characteristics of interest \\
\hline Khorana $^{12}$ & $\begin{array}{l}\text { Site of cancer: } \\
\text { Very high risk: stomach, pancreas } \\
\text { High risk: lung, lymphoma, gynecological, bladder, } \\
\text { testicular } \\
\text { Prechemotherapy platelet count } \geq 350 \times 10^{9} / \mathrm{L} \\
\text { Hemoglobin level }<10 \mathrm{~g} / \mathrm{dL} \text { or use of red cell growth } \\
\text { factors } \\
\text { Prechemotherapy leukocyte count }>11 \times 10^{9} / \mathrm{L} \\
\text { Body mass index } \geq 35 \mathrm{~kg} / \mathrm{m}^{2}\end{array}$ \\
\hline Vienna $^{75}$ & $\begin{array}{l}\text { Khorana score plus the following: } \\
\text { Soluble P-selectin, D-dimer }\end{array}$ \\
\hline Protecht $^{74}$ & $\begin{array}{l}\text { Khorana score plus the following: } \\
\text { Use of platinum-based therapy } \\
\text { Use of gemcitabine }\end{array}$ \\
\hline
\end{tabular}

apixaban group compared with the placebo group ( $4.2 \%$ vs $10.2 \%$, HR $0.41,95 \%$ CI $0.26-0.65, p<0.001$, number needed to treat of 17). Major bleeding was higher in the apixaban group compared with the placebo group (3.5\% vs $1.8 \%$, HR $2.00,95 \%$ CI $1.01-3.95, p=0.046)$ in the intention-to-treat analysis, although analysis limited to the treatment period (median duration 157 days vs 155 days) showed that the bleeding rate was not significantly higher ( $2.1 \%$ vs $1.1 \%$, HR $1.89,95 \%$ CI 0.39 to 9.24 , number needed to harm of 100). There was no difference in nonmajor bleeding or mortality. No fatal bleeds or bleeds into critical organs occurred.

The CASSINI trial ${ }^{77}$ is a double-blind, randomized, placebo-controlled, parallel-group, multicenter study comparing 6 months of rivaroxaban (10 $\mathrm{mg}$ once daily) with placebo in 841 adult ambulatory patients also with a Khorana score $\geq 2$. Notably, during the screening period of this trial, compression limb ultrasound was performed and patients with evidence of DVT on ultrasound examination were excluded. During the on-treatment period (prior to any treatment discontinuation such as voluntary termination or secondary to side-effects), rivaroxaban significantly reduced the primary endpoint of VTE or VTE-related death compared with placebo $(2.62 \%$ vs $6.41 \%$, HR $0.40,95 \%$ CI 0.20 to $0.80, p=0.007$, number needed to treat of 26). However, there was no significant difference in the primary endpoint between the groups in analysis of the full observation period (180 days). Rates of major bleeding were low (1.98\% vs $0.99 \%$, HR $1.96,95 \%$ CI 0.59 to $6.49, p=0.265$, number needed to harm of 101 ), as were rates of CRNMB (2.72 vs $1.98 \%$, HR $1.34,95 \%$ CI 0.54 to $3.32, p=0.53$, number needed to harm of 135 ).

The results of these studies (summarized in Table 4) suggest that apixaban and rivaroxaban as primary thromboprophylaxis in high-risk patients may reduce the rate of VTE with largely favorable safety profiles, although these studies excluded patients with baseline organ dysfunction, which is common in real-world cancer patients.

\section{DOAC utility for extended anticoagulation}

To date, there is a paucity of studies investigating the efficacy and safety of continuing anticoagulation for cancer-associated VTE beyond the first 3-6 months (whether at full or reduced dose). Trials such as EINSTEIN CHOICE ${ }^{78}$ and AMPLIFY$\mathrm{EXT}^{79}$ have demonstrated the efficacy and safety of DOACs in extended anticoagulation for patients with VTE in the general population but these trials did not include large numbers of cancer patients. Most current guidelines recommend continuing therapy if the cancer is still present or if the patient is still receiving cancer-directed treatment. ${ }^{27,80}$ The DALTECAN $^{81}$ and TiCAT ${ }^{82}$ studies were both single-arm cohort analyses in which patients with cancer-associated VTE were treated with dalteparin or tinzaparin for 12 months. The results of these studies support the recommendation to

Table 5 Summary of published trials for primary thromboprophylaxis in high-risk patients

\begin{tabular}{|lllll|}
\hline Trial & VTE occurrence (\%) & Major bleeding (\%) & Clinically relevant non-major bleeding (\%) & Mortality (\%) \\
\hline $\begin{array}{llll}\text { AVERT } \\
\text { Apixaban vs placebo }\end{array}$ & $\begin{array}{l}4.2 \text { vs } 10.2 \\
\text { Apixaban significantly reduced the rate of VTE compared to placebo. Major bleeding was higher in the intention-to-treat } \\
\text { analysis. There was no difference in non-major bleeding }\end{array}$ \\
\hline $\begin{array}{l}\text { CASSINI } \\
\text { Rivaroxaban vs placebo }\end{array}$ & $\begin{array}{l}2.60 \text { vs } 6.4 \mathrm{I} \\
\text { Rivaroxaban significantly reduced the rate of VTE compared to placebo during the on-treatment period. There was no } \\
\text { difference in the rate of major or non-major bleeding }\end{array}$ \\
\hline
\end{tabular}

Abbreviation: VTE, venous thromboembolism. 
continue anticoagulation beyond 6 months. They demonstrated that the risk of VTE recurrence or bleeding was highest in the first 3-6 months and that risk of VTE recurrence persisted beyond 6 months, indicating a need for ongoing anticoagulation.

The most robust evidence for treatment of cancer-associated VTE with DOACs beyond the initial 6-month period comes from the previously discussed Hokusai VTE Cancer trial, which followed patients for up to 12 months. The results of this study support extended anticoagulation beyond an initial 6-month treatment period. In addition, a recent cohort study also demonstrated a reduced risk of VTE recurrence at 12 months for patients treated with rivaroxaban compared with LMWH and warfarin. ${ }^{83}$ Although the SELECT-D trial was initially intended to study patients beyond 6 months, this phase was terminated owing to slow recruitment.

\section{Conclusion}

To optimize treatment of VTE in cancer patients, clinicians must consider both the unique challenges of anticoagulation in this population as well as the risks and benefits of the various anticoagulant agents. Cancer patients have increased risks of bleeding and VTE recurrence relative to other patients with VTE. While DOACs have emerged as an attractive alternative to LMWH, there may be an excessive bleeding risk in certain patient groups, particularly those with GI malignancies. DOACs may vary in VTE prevention efficacy and bleeding risk. Recent studies have demonstrated that DOACs may be effective as primary thromboprophylaxis in high-risk cancer patients. Ongoing studies will further elucidate the optimal role of DOACs in diverse subpopulations of cancer patients and further inform best practices for anticoagulation in this patient population.

\section{Acknowledgments}

$\mathrm{H} \mathrm{Al-Samkari}$ is the recipient of the National Hemophilia Foundation-Shire Clinical Fellowship Award, which provides partial salary support.

\section{Author contributions}

AB Song wrote the first draft of the manuscript and contributed to concept and design, critical writing and revision of the intellectual content; RP Rosovsky contributed to critical revision of the intellectual content; JM Connors contributed to critical revision of the intellectual content; and $\mathrm{H}$ Al-Samkari contributed to concept and design, critical writing and revising the intellectual content. All authors contributed to data analysis, drafting and revising the article, gave final approval of the version to be published, and agree to be accountable for all aspects of the work.

\section{Disclosure}

RP Rosovsky reports grants from BMS, Janssen, and Portola, outside the submitted work; JM Connors reports personal fees from Bristol-Myers Squibb and Portola, during the conduct of the study; $\mathrm{H}$ Al-Samkari reports personal fees from Agios, outside the submitted work. The authors report no other conflicts of interest in this work.

\section{References}

1. Al-Samkari H, Connors JM. The role of direct oral anticoagulants in treatment of cancer-associated thrombosis. Cancers (Basel). 2018;10 (8). doi:10.3390/cancers 10110400

2. Agnelli G, Buller HR, Cohen A, et al. Oral apixaban for the treatment of acute venous thromboembolism. $N$ Engl J Med. 2013;369(9):799808. doi:10.1056/NEJMoa1302507

3. Investigators E, Bauersachs R, Berkowitz SD, et al. Oral rivaroxaban for symptomatic venous thromboembolism. $N$ Engl J Med. 2010;363 (26):2499-2510. doi:10.1056/NEJMoa1011205

4. Investigators E-P, Buller HR, Prins MH, et al. Oral rivaroxaban for the treatment of symptomatic pulmonary embolism. $N$ Engl $J$ Med. 2012;366(14):1287-1297. doi:10.1056/NEJMoa1114705

5. Schulman S, Kearon C, Kakkar AK, et al. Dabigatran versus warfarin in the treatment of acute venous thromboembolism. $N$ Engl J Med. 2009;361(24):2342-2352. doi:10.1056/NEJMoa0906598

6. Hokusai VTEI, Buller HR, Decousus H, et al. Edoxaban versus warfarin for the treatment of symptomatic venous thromboembolism. $N$ Engl J Med. 2013;369(15):1406-1415. doi:10.1056/NEJMoa1306638

7. Timp JF, Braekkan SK, Versteeg HH, Cannegieter SC. Epidemiology of cancer-associated venous thrombosis. Blood. 2013;122(10):17121723. doi:10.1182/blood-2012-12-471029

8. Heit JA, Silverstein MD, Mohr DN, Petterson TM, O'Fallon WM, Melton LJ 3rd. Risk factors for deep vein thrombosis and pulmonary embolism: a population-based case-control study. Arch Intern Med. 2000;160(6):809-815. doi:10.1001/archinte.160.6.809

9. Blom JW, Doggen CJ, Osanto S, Rosendaal FR. Malignancies, prothrombotic mutations, and the risk of venous thrombosis. JAMA. 2005;293(6):715-722. doi:10.1001/jama.293.6.715

10. Cronin-Fenton DP, Sondergaard F, Pedersen LA, et al. Hospitalisation for venous thromboembolism in cancer patients and the general population: a population-based cohort study in Denmark, 1997-2006. Br J Cancer. 2010;103(7):947-953. doi:10.1038/sj.bjc.6605822

11. Walker AJ, Card TR, West J, Crooks C, Grainge MJ. Incidence of venous thromboembolism in patients with cancer - a cohort study using linked United Kingdom databases. Eur J Cancer. 2013;49 (6):1404-1413. doi:10.1016/j.ejca.2012.10.021

12. Khorana AA, Francis CW. Risk prediction of cancer-associated thrombosis: appraising the first decade and developing the future. Thromb Res. 2018;164 Suppl 1:S70-S76. doi:10.1016/j. thromres.2018.01.036

13. Khorana AA, Francis CW, Culakova E, Kuderer NM, Lyman GH. Thromboembolism is a leading cause of death in cancer patients receiving outpatient chemotherapy. J Thromb Haemost. 2007;5 (3):632-634. doi:10.1111/j.1538-7836.2007.02374.x

14. Sorensen HT, Mellemkjaer L, Olsen JH, Baron JA. Prognosis of cancers associated with venous thromboembolism. $N$ Engl $J$ Med. 2000;343(25):1846-1850. doi:10.1056/NEJM200012213432504 
15. Watson HG, Keeling DM, Laffan M, Tait RC, Makris M. British Committee for Standards in H. Guideline on aspects of cancer-related venous thrombosis. $B r \quad J$ Haematol. 2015;170(5):640-648. doi: $10.1111 /$ bjh.2015.170.issue-5

16. Al-Samkari H, Connors JM. Dual anticoagulation with fondaparinux and dabigatran for treatment of cancer-associated hypercoagulability. Am J Hematol. 2018;93(6):E156-E158. doi:10.1002/ajh.v93.6

17. Beyer-Westendorf J, Werth S, Folprecht G, Weiss N. Trousseau's syndrome in a patient with adenocarcinoma of unknown primary and therapy-resistant venous thrombosis treated with dabigatran and fondaparinux. $\mathrm{Br} \quad J$ Clin Pharmacol. 2011;72(4):715-716. doi:10.1111/j.1365-2125.2011.03965.x

18. Prandoni P, Lensing AW, Piccioli A, et al. Recurrent venous thromboembolism and bleeding complications during anticoagulant treatment in patients with cancer and venous thrombosis. Blood. 2002;100 (10):3484-3488. doi:10.1182/blood-2002-03-0706

19. Levitan N, Dowlati A, Remick SC, et al. Rates of initial and recurrent thromboembolic disease among patients with malignancy versus those without malignancy. Risk analysis using Medicare claims data. Medicine (Baltimore). 1999;78(5):285-291. doi:10.1097/ 00005792-199909000-00001

20. Monreal M, Falga C, Valdes M, et al. Fatal pulmonary embolism and fatal bleeding in cancer patients with venous thromboembolism: findings from the RIETE registry. J Thromb Haemost. 2006;4 (9):1950-1956. doi:10.1111/j.1538-7836.2006.02117.x

21. Douketis JD, Crowther MA, Foster GA, Ginsberg JS. Does the location of thrombosis determine the risk of disease recurrence in patients with proximal deep vein thrombosis? Am J Med. 2001;110(7):515-519.

22. Lee AY, Levine MN, Baker RI, et al. Low-molecular-weight heparin versus a coumarin for the prevention of recurrent venous thromboembolism in patients with cancer. $N$ Engl J Med. 2003;349(2):146-153. doi:10.1056/NEJMoa030969

23. Patel HK, Khorana AA. Anticoagulation in cancer patients: a summary of pitfalls to avoid. Curr Oncol Rep. 2019;21(2):18. doi:10.1007/s11912-019-0767-5

24. Engman CA, Zacharski LR. Low molecular weight heparins as extended prophylaxis against recurrent thrombosis in cancer patients. $J$ Natl Compr Cancer Netw. 2008;6(7):637-645. doi:10.6004/jnccn.2008.0050

25. Farge D, Debourdeau P, Beckers M, et al. International clinical practice guidelines for the treatment and prophylaxis of venous thromboembolism in patients with cancer. J Thromb Haemost. 2013;11(1):56-70. doi:10.1111/jth.12070

26. Kearon C, Akl EA, Comerota AJ, et al. Antithrombotic therapy for VTE disease: antithrombotic therapy and prevention of thrombosis, 9th ed: American College of chest physicians evidence-based clinical practice guidelines. Chest. 2012;141(2 Suppl):e419S-e496S.

27. Lyman GH, Khorana AA, Kuderer NM, et al. Venous thromboembolism prophylaxis and treatment in patients with cancer: American Society of Clinical Oncology clinical practice guideline update. $J$ Clin Oncol. 2013;31(17):2189-2204. doi:10.1200/JCO.2013.49.0219

28. Kahale LA, Hakoum MB, Tsolakian IG, et al. Anticoagulation for the long-term treatment of venous thromboembolism in people with cancer. Cochrane Database Syst Rev. 2018;6:CD006650.

29. Sobieraj DM, Baker WL, Smith E, et al. Anticoagulation for the treatment of cancer-associated thrombosis: a systematic review and network meta-analysis of randomized trials. Clin Appl Thromb Hemost. 2018 Sep 24:1076029618800792. doi:10.1177/ 1076029618800792.

30. Lee AYY, Kamphuisen PW, Meyer G, et al. Tinzaparin vs Warfarin for treatment of acute venous thromboembolism in patients with active cancer: a randomized clinical trial. JAMA. 2015;314(7):677686. doi:10.1001/jama.2015.9243

31. Khorana AA, McCrae KR, Milentijevic D, et al. Current practice patterns and patient persistence with anticoagulant treatments for cancer-associated thrombosis. Res Pract Thromb Haemost. 2017;1 (1):14-22. doi:10.1002/rth2.12002
32. van Es N, Coppens M, Schulman S, Middeldorp S, Buller HR. Direct oral anticoagulants compared with vitamin $\mathrm{K}$ antagonists for acute venous thromboembolism: evidence from phase 3 trials. Blood. 2014;124(12):1968-1975. doi:10.1182/blood-2014-04-571232

33. Raskob GE, van Es N, Verhamme P, et al. Edoxaban for the treatment of cancer-associated venous thromboembolism. $N$ Engl $J$ Med. 2018;378(7):615-624. doi:10.1056/NEJMoa1711948

34. Young AM, Marshall A, Thirlwall J, et al. Comparison of an oral factor xa inhibitor with low molecular weight heparin in patients with cancer with venous thromboembolism: results of a randomized trial (SELECT-D). J Clin Oncol. 2018;36(20):2017-2023. doi:10.1200/ JCO.2018.78.8034

35. McBane RD, Wysokinski W, Le-Rademacher J, et al. Apixaban, Dalteparin, in active cancer associated venous thromboembolism, the ADAM VTE trial. San Diego, CA: 2018 Annual Meeting of the American Society for Hematology; December 2018.

36. McBane R 2nd, Loprinzi CL, Ashrani A, et al. Apixaban and dalteparin in active malignancy associated venous thromboembolism. Thromb Haemost. 2017;117(10):1952-1961. doi:10.1160/TH17-03-0193

37. Li A, Garcia DA, Lyman GH, Carrier M. Direct oral anticoagulant (DOAC) versus low-molecular-weight heparin (LMWH) for treatment of cancer associated thrombosis (CAT): a systematic review and meta-analysis. Thromb Res. 2019 Jan;173:158-163. doi:10.1016/ j.thromres.2018.02.144.

38. Rossel A, Robert-Ebadi H, Combescure C, et al. Anticoagulant therapy for acute venous thrombo-embolism in cancer patients: a systematic review and network meta-analysis. PLoS One. 2019;14 (3):e0213940. doi:10.1371/journal.pone.0213940

39. Elsebaie MAT, van Es N, Langston A, Buller HR, Gaddh M. Direct oral anticoagulants in patients with venous thromboembolism and thrombophilia: a systematic review and meta-analysis. J Thromb Haemost. 2019;17(4):645-656. doi:10.1111/jth.14398

40. Li A, Garcia DA, Lyman GH, Carrier M. Direct oral anticoagulant (DOAC) versus low-molecular-weight heparin (LMWH) for treatment of cancer associated thrombosis (CAT): a systematic review and meta-analysis. Thromb Res. 2019;173:158-163. doi:10.1016/j. thromres.2018.02.144

41. Connolly SJ, Ezekowitz MD, Yusuf S, et al. Dabigatran versus warfarin in patients with atrial fibrillation. $N$ Engl J Med. 2009;361 (12):1139-1151. doi:10.1056/NEJMoa0905561

42. Desai J, Kolb JM, Weitz JI, Aisenberg J. Gastrointestinal bleeding with the new oral anticoagulants-defining the issues and the management strategies. Thromb Haemost. 2013;110(2):205-212. doi:10.1160/TH1302-0150

43. Patel MR, Mahaffey KW, Garg J, et al. Rivaroxaban versus warfarin in nonvalvular atrial fibrillation. $N$ Engl J Med. 2011;365(10):883891. doi:10.1056/NEJMoa1009638

44. Kraaijpoel N, Di Nisio M, Mulder FI, et al. Clinical impact of bleeding in cancer-associated venous thromboembolism: results from the Hokusai VTE Cancer Study. Thromb Haemost. 2018;118 (8):1439-1449. doi:10.1055/s-0038-1667001

45. Zakai NA, Walker RF, MacLehose RF, Adam TJ, Alonso A, Lutsey PL. Impact of anticoagulant choice on hospitalized bleeding risk when treating cancer-associated venous thromboembolism. $J$ Thromb Haemost. 2018. doi:10.1111/jth.14303

46. Soff G, Sarasohn D, Haegler-Laube E, et al. Safe and effective use of rivaroxaban for treatment of cancer associated venous thromboembolic disease. San Diego, CA: 2018 Annual Meeting of the American Society for Hematology; December 2018.

47. Agnelli G, Becattini C, Bauersachs R, et al. Apixaban versus Dalteparin for the treatment of acute venous thromboembolism in patients with cancer: the Caravaggio Study. Thromb Haemost. 2018;118(9):1668-1678. doi:10.1055/s-0038-1668523

48. Carney BJ, Uhlmann EJ, Puligandla M, et al. Intracranial hemorrhage with direct oral anticoagulants in patients with brain tumors. $J$ Thromb Haemost. 2019;17(1):72-76. doi:10.1111/jth.14336 
49. Khorana AA, Noble S, Lee AYY, et al. Role of direct oral anticoagulants in the treatment of cancer-associated venous thromboembolism: guidance from the SSC of the ISTH. J Thromb Haemost. 2018;16(9):1891-1894. doi:10.1111/jth.14219

50. Soff GA. Use of direct oral anticoagulants for treating venous thromboembolism in patients with cancer. J Natl Compr Cancer Netw. 2018;16(5S):670-673. doi:10.6004/jnccn.2018.0041

51. Riess H, Prandoni P, Harder S, Kreher S, Bauersachs R. Direct oral anticoagulants for the treatment of venous thromboembolism in cancer patients: potential for drug-drug interactions. Crit Rev Oncol Hematol. 2018;132:169-179. doi:10.1016/j.critrevonc.2018.09.015

52. Hutchinson A, Rees S, Young A, Maraveyas A, Date K, Johnson MJ. Oral anticoagulation is preferable to injected, but only if it is safe and effective: an interview study of patient and carer experience of oral and injected anticoagulant therapy for cancer-associated thrombosis in the select-d trial. Palliat Med. 2019;33(5):510-517.

53. Noble S, Matzdorff A, Maraveyas A, Holm MV, Pisa G. Assessing patients' anticoagulation preferences for the treatment of cancerassociated thrombosis using conjoint methodology. Haematologica. 2015;100(11):1486-1492. doi:10.3324/haematol.2015.127126

54. Cimminiello C, Anderson FA Jr. Physician and patient perceptions of the route of administration of venous thromboembolism prophylaxis: results from an international survey. Thromb Res. 2012;129(2):139145. doi:10.1016/j.thromres.2011.07.017

55. Farge D, Bounameaux H, Brenner B, et al. International clinical practice guidelines including guidance for direct oral anticoagulants in the treatment and prophylaxis of venous thromboembolism in patients with cancer. Lancet Oncol. 2016;17(10):e452-e466. doi:10.1016/S1470-2045(16)30369-2

56. Elalamy I, Mahe I, Ageno W, Meyer G. Long-term treatment of cancer-associated thrombosis: the choice of the optimal anticoagulant. J Thromb Haemost. 2017;15(5):848-857. doi:10.1111/jth.13659

57. Al-Samkari H, Connors JM. Anticoagulation and enzalutamide: caution over convenience. J Oncol Pract. 2017;13(11):728-729. doi:10.1200/JOP.2017.027664

58. Pollack CV Jr., Reilly PA, Eikelboom J, et al. Idarucizumab for dabigatran reversal. $N$ Engl $J$ Med. 2015;373(6):511-520. doi:10.1056/NEJMoa1502000

59. Connolly SJ, Milling TJ Jr, Eikelboom JW, et al. Andexanet Alfa for acute major bleeding associated with factor Xa inhibitors. $N$ Engl $J$ Med. 2016;375(12):1131-1141. doi:10.1056/NEJMoa1607887

60. Ansell JE, Bakhru SH, Laulicht BE, et al. Use of PER977 to reverse the anticoagulant effect of edoxaban. $N$ Engl J Med. 2014;371 (22):2141-2142. doi:10.1056/NEJMc1411800

61. Weber J, Olyaei A, Shatzel J. The efficacy and safety of direct oral anticoagulants in patients with chronic renal insufficiency: a review of the literature. Eur J Haematol. 2019;102(4):312-318. doi:10.1111/ejh.13208

62. Kooiman J, Den Exter PL, Cannegieter SC, et al. Impact of chronic kidney disease on the risk of clinical outcomes in patients with cancerassociated venous thromboembolism during anticoagulant treatment. $J$ Thromb Haemost. 2013;11(11):1968-1976. doi:10.1111/jth.12411

63. Lyman GH, Bohlke K, Falanga A; American Society of Clinical O. Venous thromboembolism prophylaxis and treatment in patients with cancer: American Society of Clinical Oncology clinical practice guideline update. J Oncol Pract. 2015;11(3):e442-444. doi:10.1200/ JOP.2015.004473

64. Wang T-F, Li A, Garcia D. Managing thrombosis in cancer patients. Res Pract Thromb Haemost. 2018;2(3):429-438. doi:10.1002/rth2.12102

65. Khorana AA, Francis CW, Culakova E, Kuderer NM, Lyman GH. Frequency, risk factors, and trends for venous thromboembolism among hospitalized cancer patients. Cancer. 2007;110(10):23392346. doi:10.1002/cncr.23062

66. Lyman GH, Khorana AA, Falanga A, et al. American Society of Clinical Oncology guideline: recommendations for venous thromboembolism prophylaxis and treatment in patients with cancer. $J$ Clin Oncol. 2007;25(34):5490-5505. doi:10.1200/JCO.2007.14.1283
67. Khorana AA, Kuderer NM, Culakova E, Lyman GH, Francis CW. Development and validation of a predictive model for chemotherapyassociated thrombosis. Blood. 2008;111(10):4902-4907. doi:10.1182/ blood-2007-10-116327

68. Khorana AA, Kamphuisen PW, Meyer G, et al. Tissue factor as a predictor of recurrent venous thromboembolism in malignancy: biomarker analyses of the CATCH trial. J Clin Oncol. 2017;35 (10):1078-1085. doi:10.1200/JCO.2016.67.4564

69. Khorana AA, Rao MV. Approaches to risk-stratifying cancer patients for venous thromboembolism. Thromb Res. 2007;120 Suppl 2:S41S50. doi:10.1016/S0049-3848(07)70129-9

70. Ay C, Simanek R, Vormittag R, et al. High plasma levels of soluble Pselectin are predictive of venous thromboembolism in cancer patients: results from the Vienna Cancer and Thrombosis Study (CATS). Blood. 2008;112(7):2703-2708. doi:10.1182/blood-2008-02-142422

71. Pabinger I, van Es N, Heinze G, et al. A clinical prediction model for cancer-associated venous thromboembolism: a development and validation study in two independent prospective cohorts. Lancet Haematol. 2018;5(7):e289-e298. doi:10.1016/S2352-3026(18)30063-2

72. Parker A, Peterson E, Lee AYY, et al. Risk stratification for the development of venous thromboembolism in hospitalized patients with cancer. $J$ Thromb Haemost. 2018;16(7):1321-1326. doi:10.1111/jth.14139

73. Patell R, Rybicki L, McCrae KR, Khorana AA. Predicting risk of venous thromboembolism in hospitalized cancer patients: utility of a risk assessment tool. Am J Hematol. 2017;92(6):501-507. doi:10.1002/ajh.24700

74. Verso M, Agnelli G, Barni S, Gasparini G, LaBianca R. A modified Khorana risk assessment score for venous thromboembolism in cancer patients receiving chemotherapy: the Protecht score. Intern Emerg Med. 2012;7(3):291-292. doi:10.1007/s11739-012-0784-y

75. Ay C, Dunkler D, Marosi C, et al. Prediction of venous thromboembolism in cancer patients. Blood. 2010;116(24):5377-5382. doi:10.1182/blood-2010-02-270116

76. Carrier M, Abou-Nassar K, Mallick R, et al. Apixaban to prevent venous thromboembolism in patients with cancer. $N$ Engl J Med. 2019;380(8):711-719. doi:10.1056/NEJMoa1814468

77. Khorana AA, Soff GA, Kakkar AK, et al. Rivaroxaban for thromboprophylaxis in high-risk ambulatory patients with cancer. $N$ Engl J Med. 2019;380(8):720-728. doi:10.1056/NEJMoa1814630

78. Pollack CV Jr., Bernstein R, Dubiel R, et al. Healthcare resource utilization in patients receiving idarucizumab for reversal of dabigatran anticoagulation due to major bleeding, urgent surgery, or procedural interventions: interim results from the RE-VERSE AD study. $J$ Med Econ. 2017;20(5):435-442. doi:10.1080/13696998.2016.1273229

79. Agnelli G, Buller HR, Cohen A, et al. Apixaban for extended treatment of venous thromboembolism. N Engl J Med. 2013;368(8):699708. doi:10.1056/NEJMoa1207541

80. Streiff MB, Holmstrom B, Angelini D, et al. NCCN guidelines insights: cancer-associated venous thromboembolic disease, version 2.2018. J Natl Compr Cancer Netw. 2018;16(11):1289-1303. doi:10.6004/jncen.2018.0084

81. Francis CW, Kessler CM, Goldhaber SZ, et al. Treatment of venous thromboembolism in cancer patients with dalteparin for up to 12 months: the DALTECAN Study. J Thromb Haemost. 2015;13 (6):1028-1035. doi:10.1111/jth. 12923

82. Jara-Palomares L, Solier-Lopez A, Elias-Hernandez T, et al. Tinzaparin in cancer associated thrombosis beyond 6months: TiCAT study. Thromb Res. 2017;157:90-96. doi:10.1016/j.thromres.2017.07.004

83. Streiff MB, Milentijevic D, McCrae K, et al. Effectiveness and safety of anticoagulants for the treatment of venous thromboembolism in patients with cancer. Am J Hematol. 2018;93(5):664-671. doi:10.1002/ajh.25059

84. Meyer G, Marjanovic Z, Valcke J, et al. Comparison of low-molecular-weight heparin and warfarin for the secondary prevention of venous thromboembolism in patients with cancer: a randomized controlled study. Arch Intern Med. 2002;162(15):1729-1735. 
85. Lee AY, Rickles FR, Julian JA, et al. Randomized comparison of low molecular weight heparin and coumarin derivatives on the survival of patients with cancer and venous thromboembolism. J Clin Oncol. 2005;23(10):2123-2129. doi:10.1200/JCO.2005.03.133

86. Deitcher SR, Kessler CM, Merli G, et al. Secondary prevention of venous thromboembolic events in patients with active cancer: enoxaparin alone versus initial enoxaparin followed by warfarin for a 180day period. Clin Appl Thromb Hemost. 2006;12(4):389-396. doi:10.1177/1076029606293692

87. Hull RD, Pineo GF, Brant RF, et al. Long-term low-molecular-weight heparin versus usual care in proximal-vein thrombosis patients with cancer. Am J Med. 2006;119(12):1062-1072. doi:10.1016/j. amjmed.2006.02.022

88. Carrier M, Le Gal G, Cho R, Tierney S, Rodger M, Lee AY. Dose escalation of low molecular weight heparin to manage recurrent venous thromboembolic events despite systemic anticoagulation in cancer patients. J Thromb Haemost. 2009;7(5):760-765. doi:10.1111/ j.1538-7836.2009.03326.x
89. Ihaddadene R, Le Gal G, Delluc A, Carrier M. Dose escalation of low molecular weight heparin in patients with recurrent cancer-associated thrombosis. Thromb Res. 2014;134(1):93-95. doi:10.1016/j. thromres.2014.04.028

90. Schulman S, Zondag M, Linkins L, et al. Recurrent venous thromboembolism in anticoagulated patients with cancer: management and short-term prognosis. J Thromb Haemost. 2015;13(6):1010-1018. doi: $10.1111 /$ jth. 12955

91. Marshall AL, Campigotto F, Neuberg D, Rowe B, Connors JM. Recurrence of venous thromboembolism in patients with cancer treated with Warfarin. Clin Appl Thromb Hemost. 2015;21(7):632638. doi:10.1177/1076029615579099

92. Tittl L, Endig S, Marten S, Reitter A, Beyer-Westendorf I, BeyerWestendorf J. Impact of BMI on clinical outcomes of NOAC therapy in daily care - Results of the prospective Dresden NOAC Registry (NCT01588119). Int J Cardiol. 2018;262:85-91. doi:10.1016/j. ijcard.2018.03.060

\section{Publish your work in this journal}

Vascular Health and Risk Management is an international, peerreviewed journal of therapeutics and risk management, focusing on concise rapid reporting of clinical studies on the processes involved in the maintenance of vascular health; the monitoring, prevention and treatment of vascular disease and its sequelae; and the involvement of metabolic disorders, particularly diabetes. This journal is indexed on PubMed Central and MedLine. The manuscript management system is completely online and includes a very quick and fair peerreview system, which is all easy to use. Visit http://www.dovepress. com/testimonials.php to read real quotes from published authors. 